\title{
Past and future of the calcium paradox
}

\author{
D. Durrer and F. L. MeiJler \\ Interuniversity Cardiology Institute, c/o P.O. Box 16250, 3500 CG Utrecht, The Netherlands
}

KEY WORDS: Calcium paradox.

Important developments in medicine and other scientific disciplines are always reported in scientific journals in a matter of fact way. One needs a double helix ${ }^{[1]}$ or Lucy ${ }^{[2]}$ to learn more about the real problem that haunted the investigators before they were able to trust their results to a journal. Although the scientific importance of the calcium paradox (probably) cannot compete with the double helix, or the discovery of beta blockers ${ }^{[3]}$, a symposium devoted to this truly paradoxical phenomenon justifies a story in a more anecdotal form than a communication in Lancet ${ }^{[4]}$ or Nature ${ }^{[5]}$.

In the late nineteen fifties and early sixties we worked on the improvement of the set-up for the Langendorff perfusion of isolated mammalian hearts. An important goal was the revived isolated human heart on which we reported in $1970{ }^{[6]}$. The isolated perfused rat heart, small but beautiful was used for other studies at that time as well[7,8]. Dr Zimmerman worked as a medical student in the laboratory and really wanted to contribute with ideas and long hours. He had a friend $\mathrm{Dr}$ Hülsmann, physician and biochemist who was regularly consulted on the best organic substrate for the perfusion fluid.

We had already substantially altered the original Tyrode solution ${ }^{[9]}$ and obtained good results as far as longevity and contractile function of the heart were concerned. If left alone, our isolated rat hearts carried on beating for close to eight hours. But Dr Zimmerman wanted to do better and came up with the idea as suggested by Dr Hülsmann to use acetoacetate in stead of glucose, or at least in addition to glucose, as the organic substrate. The experiment was done, but instead of an improvement in the performance of the preparation we observed a mechanical arrest, combined with an intact left ventricular electrogram. We had observed our first electro-mechanical dissociation ${ }^{[4]}$. Although many experiments with isolated rat hearts were performed in those days by biochemists using acetoacetate and other substances from the Krebs cycle, nobody had observed the excitation-contraction decoupling, because biochemists in those days usually did not register the cardiac electrograms.

So, there we were with the opposite effect of acetoacetate than what we had expected. It soon turned out that we had used acetoacetate in far too high concentrations. Hülsmann developed a theory that acetoacetate, being a precursor of active acetate, might increase intracellular citrate and hence lower free $\mathrm{Ca}^{2+}$.

The logical step to follow was to compare the acetoacetate results ${ }^{[4]}$ with those to be obtained by a calcium-free perfusion fluid. And then happened what evidently nobody had reported on before. When calcium was re-introduced into the perfusate, after a calcium-free perfusion period which also resulted in an electro-mechanical dissociation, the heart muscle cells lost their constituents and were completely destroyed.

After a few very forceful contractions that occur directly at the beginning of reperfusion with calcium all contractile and electrical function of the heart ceased, because of the aforementioned destruction of ultra- and micro-structure of the myocardium. The calcium paradox was discovered $\left.{ }^{[}\right]$. The name calcium paradox was in a sense a plagiarism, being derived from the so-called potassium paradox by Zwaardemaker ${ }^{[10]}$ on which one of us had reported ten years earlier ${ }^{[11]}$.

It is now 100 years since Ringer ${ }^{[12]}$ discovered that calcium is a prerequisite for the contractile functioning of the myocardial cell. Nearly twenty years ago Zimmerman and Hülsmann discovered[5] that calcium is a prerequisite for the morphological integrity of the myocardial cell as well, thus adding an additional life conserving item to the long list of fundamental biological conditions of the calcium ion. In those past twenty years our knowledge of calcium ion physiology and pathophysiology has increased considerably ${ }^{[13]}$. Probably one of the most important spin-offs of the study of the effect of calcium on living tissue has been the discovery by Fleckenstein ${ }^{[14]}$ of the calcium antagonists. The full story has recently been told in his beautiful monograph ${ }^{[15]}$. The calcium paradox is only one aspect of the multi-faceted behaviour of the calcium ion 
in all living material, but together with its role in the myocardial excitation-contraction coupling a very important one.

At the time of its discovery it was difficult to envisage its significance for electron microscopy, physiology, pharmacology and surgery of the heart. This symposium summarizes the state of the art of the calcium paradox. We consider it an especial privilege that all those scientists that brought our knowledge of calcium ion behaviour in the myocardium to an all-time height have come to Utrecht to establish where we are and to speculate where we may go.

The future of the calcium paradox will probably rest in its significance as a model for myocardial damage also by other causes, for instance ischaemic damage. The notion that the calcium paradox and ischaemic or rather reperfusion damage are related phenomena, is generally accepted[16]. Therefore the calcium paradox may be a valuable tool for the study and development of those compounds that may protect the myocardium against reperfusion damage. Some of those drugs may ultimately also protect the myocardium against ischaemic damage due to coronary insufficiency and thus become of great value for clinical cardiology, since they may protect patients with coronary heart disease against the sequela of coronary occlusion. We expect that the application of ${ }^{31} \mathrm{P}$ nuclear magnetic resonance ${ }^{[17.18]}$ for the study of the calcium paradox will reveal the role of the high energy phosphates played in this phenomenon while also wider application of $\mathrm{NMR}^{[19]}$ may teach us more about the actual destruction of the membrane due to either calcium depletion and the calcium depletion and the calcium paradox or ischaemia and reperfusion.

The development of insights in the significance of calcium ion movements for the function and integrity of myocardial tissue demonstrates (again) that fundamental research without any seemingly significance for clinical medicine at the time of its performance may turn into one of the pillars of current day by day patient care. Both calcium paradox and calcium antagonism were regarded as esoteric hobbies of the researchers of that time. Just as the present is an extrapolation of the past teaching us that (clinical) relevance can be neither excluded nor predicted, the future of mankind will rest on fundamental research undertaken today[20,21].

\section{References}

[1] Watson JD, Tooze J. The DNA story, a documentary history of gene cloning. W.H. Freeman and Company, San Franciso, 1982.
[2] Johanson D, Edy M. Lucy, the beginnings of mankind. Simon and Schuster, New York, 1981.

[3] Black JW, Stephenson JS. Pharmacology of a new adrenergic beta-receptor-blocking compound (Nethalide). Lancet 1962; ii: $311-4$.

[4] Zimmerman ANE, Meijler FL, Hülsmann WC. The inhibitory effect of acetoacetate on myocardial contraction. Lancet 1962; ii: 757-8.

[5] Zimmerman ANE, Hülsmann WC. Paradoxical influence of calcium ions on the permeability of the cell membranes of the isolated rat heart. Nature 1966; 211: 646-7.

[6] Durrer D, Van Dam RT, Freud GE, Janse MJ, Meijler FL, Arzbaecher RC. Total excitation of the isolated human heart. Circulation 1970; 41: 899-912.

[7] Meijler FL, Van den Bogaard F, Van der Tweel LH, Durrer D. Postextrasystolic potentiation in the isolated rat heart. Am J Physiol 1962; 202: 631-5.

[8] Meijler FL, Durrer D. Influence of monoamine oxidase inhibitor on contractility of isolated rat hearts. Am J Physiol 1962; 202: 1152-4.

[9] Durrer D, Büller J, Graaff PL, Lo GI, Meijler FL. Epicardial excitation pattern as observed in the isolated revived and perfused fetal human heart. Circ Res 1961; 9: 29-38.

[10] Zwaardemaker H. Le paradoxe Radio-physiologique. C R Soc Biol (Paris) 1921; 84: 704-6.

[11] Meijler FL. Sur l'action de l'acéthylcholine, de l'atropine et du potassium sur le coeur de la grenouille. Arch Int Physiol 1953; 61: 323-9.

[12] Ringer S. A further contribution regarding the influence of the different constituents of the blood on the contraction of the heart. J Physiol 1883; 4: 29-42.

[13] Nayler WG, Merrillees NCR. Cellular exchange of calcium. In: Harris P, Opie LH, eds. Calcium and the heart. London, Academic Press, 1971: 24-65.

[14] Fleckenstein A. Pharmacology and electrophysiology of calcium antagonists In: Calcium Antagonism in cardiovascular therapy. Editors: Zanchette A, Krikler DM. Excerpta Medica 1981: 10-30.

[15] Fleckenstein A. Calcium antagonism in heart and smooth muscle. John Wiley and Sons, New York, 1983.

[16] Ruigrok TJC. The calcium paradox: mechanisms and clinical relevance. In: Anghileri LJ, TuffetAnghileri AM, eds. The role of calcium in biological systems, Vol. 3. Boca Raton, FL: CRC Press, 1982: 133-141.

[17] Bulkley BH, Nunnally RL, Hollis DP. 'Calcium paradox' and the effect of varied temperature on its development: a phosphorus nuclear magnetic resonance and morphologic study. Lab Invest 1978; 39: 133-40.

[18] Ruigrok TJC, Van Echteld CJA, De Kruijff B, Borst C, Meijler FL. Protective effect of nifedipine in myocardial ischemia assessed by phosphorus-31 nuclear magnetic resonance. Eur Heart J 1983; 4 (suppl. C): 109-113.

[19] Gadian DG. Nuclear magnetic resonance and its applications to living systems. Oxford University Press, Oxford, 1982.

[20] Burchell HB. The relevance of irrelevance. Circulation $1973 ; 47$ : 1-6.

[21] Meijler FL. The relevance of 'irrelevant' research. Eur J Cardiol 1978; 7: 1-5. 